\title{
Roman Rosdolsky (1898-1967): \\ um intelectual em tempos de extremos
}

João Antonio de Paula Professor do Cedeplar/FACE/UFMG

\section{Palavras-chave}

Roman Rosdolsky

(1898-1967), marxismo.

Classificação JEL B24, B31.

\section{Resumo}

$\mathrm{O}$ artigo apresenta a trajetória intelectual de Roman Rosdolsky, destacando suas contribuições para a interpretação da obra de Marx e para os estudos de história.

\section{Abstract}

This article presents the intellectual trajectory of Roman Rosdolsky, bighlighting his contributions to the interpretation of Marx's works and to the historical studies.

Key words

Roman Rosdolsky (1898-1967), Marxism.

JEL Classification B24, B31. 
Nosso tempo, disse Hobsbawm, tem sido "interessante" e tem alcançado extremos. Tempos interessantes foi o nome que ele deu a seu livro de memórias, publicado em 2002. O quarto volume de sua tetralogia, sobre a história do capitalismo, chama-se Era dos extremos, e aborda o que ele chamou de "curto século XX", que teria começado com a primeira grande guerra e se encerrado com o fim da URSS, em 1991. Para Hobsbawm o século passado foi marcado por demasias, por paroxismos de toda ordem: da tragédia à abjeção, do sublime ao grotesco, da barbárie a esperanças fortemente auspiciosas.

É sob essa dupla clivagem - a que remete ao interessante e movimentado, mas que também não quer eludir a barbárie, que também ela esteve presente - que se deve considerar a figura que se quer evocar aqui.

Nascido na Galícia, em 1898, região então pertencente ao Império AustroHúngaro, e morto em Detroit, nos Estados Unidos, em 1967, Roman Rosdolsky, militante político, historiador, economista, escritor, professor é desses indivíduos para os quais a vida é um permanente turbilhão, testemunha e sujeito de acontecimentos e processos decisivos do século XX.

Que esse verdadeiramente grande nome do pensamento social não seja devidamente conhecido não é particularidade brasileira. De fato, tanto as circunstâncias incisivamente dramáticas de sua vida quanto o sentido mesmo de suas escolhas éticopolíticas se salvaram-no da celebridade frívola, de outro lado condenaram-no, ao seu nome e a sua obra, ao quase anonimato.

Estudante em Praga e Viena, no período terminal do Império Austro-Húngaro, Roman Rosdolsky emigrou para os Estados Unidos, em 1947, país onde não ocupará qualquer posição acadêmica de relevo com exceção de um curto período, entre 1949 e 1951, quando lecionou História na Wayne State University, de Detroit. Escreveu o principal de sua obra em russo e alemão. Isso tudo terá contribuído também para explicar o pouco que dele se sabe. Uma busca na rede mundial de computadores sobre Roman Rosdolsky traz pequenos e insatisfatórios resultados. Fora a listagem do material constante do arquivo Roman Rosdolsky Papers, o texto mais informado sobre ele é de Ernest Mandel, tradução para o holandês de um artigo escrito para a revista Quatrième Internationale, $\mathrm{n}^{\circ} 33$, de abril de 1968. Além do texto de Mandel, cite-se também o artigo de Anson Rabinbach que traz alguns poucos dados biográficos retirados da biografia de Rosdolsky escrita por sua esposa - Emily - "Ueber den Autor", que está nos Studien über revolutionäre tatik, de Roman Rosdolsky, pu- 
blicado em Berlim, em 1973 (Rabinbach, 1974, p. 52).

Mesmo a pequena informação que circula sobre Roman Rosdolsky não está isenta de imprecisão. Num dos textos da internet, a data de seu nascimento aparece como 18 de julho de 1898, noutro a data reportada é 19 de julho de 1898. Também a data de sua morte é imprecisa nesses textos: 15 de outubro de 1967, 20 de outubro de 1967, enquanto Ernest Mandel, sem precisar o dia, diz que Rosdolsky morreu em novembro de 1967.

Com efeito, Roman Rosdolsky é conhecido, quando o é, sobretudo, pelo seu notável livro sobre os Grundrisse de Marx, obra publicada em alemão em 1968, com o título Zur Entstehungsgeschichte des Marxschen Kapital, e que, traduzido para o português, por iniciativa de César Benjamin, foi publicado no Brasil, em 2001, com o título Gênese e estrutura de "O Capital" de Karl Marx (Rosdolsky, 2001).

A vida de Rosdolsky, em mais de um aspecto, reflete em sua irredutível singularidade, as vicissitudes de toda uma época, tal como essa pode ser vivida por quem fez escolhas políticas, éticas e intelectuais à contrapelo da ordem.

Roman Rosdolsky, revolucionário, marxista, comunista, trotsquista, feito prisioneiro em campos de concentração nazista viveu "a era dos extremos" em alguns de seus limites: a Primeira Grande Guerra; a Revolução Russa; a decomposição dos velhos impérios; a ascensão do nazi-fascismo; as hiperinflações; a luta política e a degeneração burocrática da Revolução Russa; a crise capitalista avassaladora dos anos 1930; as emergências do Estado Keynesiano de Bem-Estar Social; a barbárie nazista e a Segunda Grande Guerra; os anos de ouro do capitalismo pós-1945.

Como já dito, Roman Rosdolsky nasceu na Galícia, na cidade de Lemberg (hoje chamada Lvov), em 1898, cidade pertencente, então, ao Império AustroHúngaro. Tal como a região homônima na Espanha, essa Galícia também tem sua história ligada às migrações célticas. No passado, tal Galícia celta no mundo eslavo foi dividida, sendo sua parte ocidental incorporada à Polônia (as regiões de Cracóvia e Rzeszow), enquanto a parte oriental passou ao controle da Ucrânia, também chamada de Rússia Branca ou Rússia Kieviana (as regiões de Lvov, Ivano, Frankovsk, Drogobytch e Tecnopol). No século XII, a Galícia oriental tornou-se independente da Rússia Kieviana, sendo anexada à Polônia, em 1349, por Casimir III. Em 1772, na primeira repartição da Polônia, a Galícia foi atribuída à Áustria. A dominação austríaca sobre a região manteve-se, no essencial, até a Primeira Guerra Mundial, quando foi palco de violentos combates. 
Anexada à Polônia em 1918, a Galícia foi alvo de disputa entre rutenos ucranianos e poloneses durante as décadas seguintes. Em 1945, a Conferência de Potsdam dividiu, novamente, a Galícia atribuindo a parte oriental à Ucrânia e a parte ocidental à Polônia.

Se é costumeiro, e justificado, atribuir-se à Polônia destino infausto pelas recorrentes agressões que sofreu por parte de seus poderosos vizinhos (Rússia - Áustria Prússia-Alemanha), esse quadro fica ainda mais dramático se se considerar a situação da Galícia, região ainda mais humilhada e esbulhada, porque periferia de periferia.

Recrutado pelo exército austríaco em 1915, Rosdolsky já nessa época era militante socialista, membro dos Círculos Drabomanov. Em 1917 edita, na Galícia, juntamente com Roman Turiansky, o jornal Klic. Participa, em 1918, da fundação, na Galícia Polonesa, da organização clandestina Social Democracia Revolucionária Internacional. Foi membro do Comitê Central do Partido Comunista da Galicia Oriental, entre 1921 e 1924, representando os militantes exilados. Inicialmente simpático às posições de Bukharin, Rosdolsky, em 1924, recusou-se a apoiar a condenação à Oposição de Esquerda, bloco interno ao Partido Comunista Russo, liderado por Trotsky, no momento em que a luta interna do partido se intensificou, com a morte de Lênin, em janeiro de 1924. Membro da corrente trotsquista a partir de 1924, Rosdolsky será expulso do Partido Comunista da Galícia Oriental, no mesmo contexto em que se deu a queda de Trotsky, sua expulsão do partido e do país, no final dos anos 1920, momento do início da dominação stalinista.

Terminada a Primeira Grande Guerra, Rosdolsky mudou-se para Praga, onde estudou Direito. Logo em seguida vai para Viena, cidade onde viveu seus decisivos anos de formação. Rosdolsky morou em Viena até 1934, quando, com a chegada ao governo de Dolfuss, líder do Partido Católico Conservador, teve início uma dura repressão à esquerda socialista e revolucionária, motivando a volta de Rosdolsky para a Galícia.

Em Viena Rosdolsky estudou Direito, História e Ciência Política, defendendo tese de doutorado, em 1929, com o título Marx e Engels e o problema dos povos sem história (Das Problem der geschichtslosen Völker bei K. Marx und Fr. Engels), publicado em inglês em 1964, em que ele discute as Revoluções de 1848-1849, na Europa, do ponto de vista da afirmação das identidades dos povos que Hegel chamou "sem história", isto é, que tinham construído "estados", ou que tinham dificuldade de fazê-lo autonomamente, como é o caso, entre outros, das na- 
cionalidades eslavas sob o domínio russo/ prussiano/austríaco.

Como estudante da Universidade de Viena, Rosdolsky foi aluno de Victor Adler, a primeira grande liderança da corrente chamada Austro-Marxista, que pouco influenciou o seu marxismo, que nada reteve do Kantismo, que Victor Adler tentou insuflar no marxismo a partir do seu livro, de 1904, Causalidade e teleologia na disputa sobre a ciência. De fato, Rosdolsky defenderá, em sua principal obra, a centralidade da dialética hegeliana na obra de Marx.

Rosdolsky foi membro correspondente do Instituto Marx-Engels, de Moscou, de 1926 a 1931, experiência que foi decisiva em sua carreira como pesquisador, na medida em que o Instituto Marx-Engels, dirigido por David Riazanov, era, então, o maior repositório de documentação sobre o marxismo e o movimento socialista. Foi ali que ele tomou conhecimento da existência dos vários manuscritos inéditos de Marx, entre eles de os Grundrisse, que só serão publicados em 1939, e que terão decisiva influência em sua vida como pesquisador.

Rosdolsky casou-se em 1927, com Emily, que teve papel decisivo tanto em sua vida profissional e política quanto no plano afetivo.

Em 1964, Rosdolsky retornou a Lvov, passando a lecionar História Econômica na universidade local. Continuou sua militância política, editando, entre 1934 e 1938, o periódico de filiação trotsquista Zittja $i$ slovo. É nesse período que ficou conhecendo o grande marxista polonês Isaac Deutscher, de quem ficará amigo e com quem manterá uma rica correspondência por muitos anos. De seus primeiros anos em Lvov, é a publicação, em 1936, de seu primeiro estudo histórico sobre a realidade agrária da Galícia - (Wspólnota Gminna w byl. Galiaji i jej zanik) - A comunidade aldeã da $G a$ lícia Oriental e sua dissolução. A Segunda Guerra Mundial interrompeu a publicação de outro grande trabalho de Rosdolsky sobre o campesinato da Galícia, que só foi editado em 1962 (Rabinbach, 1974, p. 57).

Em 1939, com o início da Segunda Guerra, a Galícia foi ocupada pelo Exército Soviético em conseqüência do Tratado entre Hitler e Stálin. Em 1942, Rosdolsky foi preso em Cracóvia, pela Gestapo, por suas atividades políticas antinazistas, sobretudo por sua ajuda à população judaica da região. Preso, sobreviveu a três "campos de concentração" - Auschwitz, Ravensbrück e Oranienburg. Rosdolsky nos deu relato impressionante de sua passagem por aqueles "campos da morte", em que ele denuncia tanto os extremos da barbárie quanto analisa os aspectos econômicos dos campos de concentração. Diz ele

Auschwitr não é apenas um 'campo de morte' mas, também, um enorme campo de 
trabalho forçado, com vários campos subsidiários espalhados por considerável território; com uma média de 80.000 escravos do Reich Alemão. Ele era um sui generis 'estado dentro do estado', com uma série de indústrias, minas e mesmo empresas agrícolas (Rosdolsky, 1988, p. 34).

Esse texto dá conta de uma aguda sensibilidade de historiador, história que, junto com os estudos sobre a obra de Marx, foi o campo ao qual Rosdolsky mais se dedicou e o ponto alto da sua obra.

Vários são os trabalhos significativos de Rosdolsky no campo da história econômica, destacando-se os estudos sobre os regimes agrários da Galícia, Ucrânia, Polônia, Alemanha e Áustria. Rosdolsky também publicou estudos importantes no campo da história do movimento socialista, como é o caso do livro Estudos sobre a tática revolucionária. Dois trabalhos inéditos sobre a II Internacional e a Social-Democracia Austríaca, publicados na Alemanha, em 1973 (Mehrav, 1985, p. 284).

Se são notáveis seus trabalhos no campo historiográfico, é forçoso reconhecer que a obra-prima de Rosdolsky é seu livro sobre os Grundrisse de Marx. De fato, se a esse texto se agregar o artigo "O significado de 'O Capital' para a pesquisa marxista contemporânea", (Rosdolsky, 1972), terse-á um conjunto, que, junto com as obras de Preobrazhenski e de Rubin, são os três momentos mais altos da crítica da economia política no século XX, momentos de máxima iluminação teórica, que não se empalidecem mesmo quando confrontadas com os textos de Marx (Preobrazhenski, 1968; Rubin, 1974).

Em 1967, Ernest Mandel deu notícia da anunciada publicação do livro de Rosdolsky sobre os Grundrisse. Disse ele:

R. Rosdolsky indica a esse propósito que a publicação dos Grundrisse constitui uma verdadeira revelação e que essa obra 'por assim dizer' nos introduziu no laboratório econômico de Marx, e revelou todas as finezas, todos os caminhos de sua metodologia.

Esse autor, que é um dos melhores conhecedores de Marx, anuncia a publicação de um livro Zur Entstehungsgeschichte des Marxschen Kapital nas edições Europaische Verlagsanstalt, em Frankfurt (Mandel, 1968, p. 105), que de fato foi editado em 1968.

Publicado em alemão em 1939, os Grundrisse foram objeto de interpretações significativas como as de Martin Nicolaus, em 1973, que apareceu como introdução à edição inglesa de os Grundrisse; de Enrique Dussel, em 1985, La producción teórica de Marx. Un comentario a los Grundrisse (Dussell, 1985). O "Marx Desconhecido", de Martin Nicolaus, foi, mais de uma vez, editado em por- 
tuguês, constando do volume publicado em 2003, organizado por César Benjamin, Marx e o Socialismo (Benjamin, 2006).

Tanto Martin Nicolaus quanto Enrique Dussell buscaram reconhecer em os Grundrisse, em que pesem diferenças de abordagem, momento importante na elaboração da "crítica da economia à política" de Marx. Em sentido contrário, vai a interpretação de Keith Tribe, que, influenciado por Althusser, teria visto os "Grundrisse como um 'incoerente' e 'transicional' estágio para a 'ruptura definitiva' de Marx, seja com a economia política ricardiana, seja com as noções de alienação, que caracterizam seus primeiros trabalhos" (Rabinbach, 1974, p. 59). Se Keith Tribe é, radicalmente, antihegeliano, Martin Nicolaus também o será em termos, na medida em que questiona a adesão do Marx de os Grundrisse a uma dialética da identidade, "enquanto a dialética marxista de $O$ Capital manifestaria uma dialética da não-identidade” (Rabinbach, 1974, p. 59).

Toda a questão para Nicolaus seria o "falso ponto de partida" representado pelo fato de os Grundrisse não se iniciar pela análise da mercadoria. Com efeito, essa é questão decisiva, mas sua efetiva apreensão pressupõe reconhecer que a obra não "nasceu pronta e acabada", que é resultado de uma relativamente longa maturação. Nesse sentido, quando Marx, em 1880, nas Glosas Marginais ao "Tratado de Economia Politica", de Adolph Wagner (Marx, 1977), insistiu em afirmar a centralidade da mercadoria, essa afirmação representa o desenlace de um itinerário teórico e conceitual, que se construiu aos poucos. Para quem se dispõe a acompanhar o processo de elaboração conceitual de Marx, é desconcertante ler em uma carta dirigida a Engels, em 29 de dezembro de 1858, que relata a redação do texto da assim Contribuição à crítica da economia política, a intenção de fazer da análise de mercadoria o ponto de partida do livro. Diz Marx:

minha mulber está copiando de novo o manuscrito, que não poderá sair antes do final do mês. As razões deste atraso são: grandes periodos de indisposição física, situação que não terminou agora com o inverno. Demasiados problemas domésticos e econômicos. Finalmente: a primeira parte resultou mais importante porque, dos dois primeiros capitulos, o primeiro (A MERCADORIA) não estava redigido em absoluto no projeto inicial, e o segundo (O DINHEIRO, OU A CIRCULAÇÃO SIMPLES) não estava escrito senão esquematicamente, e depois foram tratados com mais detalhes que eu pensava a princípio... (Marx e Engels, 1974, p. 83).

Pela correspondência de Marx, é possível, então, identificar o momento em que a estrutura expositiva da crítica da economia política adquire seu formato defini- 
tivo. Esse momento situou-se entre 2 de abril de 1858, quando Marx, em carta a Engels, ainda continua considerando o ponto de partida de sua obra como o Valor, e 29 de novembro de 1858, quando a mercadoria aparece como categoria inicial da exposição. Não há nas cartas qualquer esclarecimento do que o teria levado à mudança. De todo modo, trata-se de acontecimento essencial, ponto culminante do itinerário de Marx na construção de sua crítica da economia política.

Se é assim, então a obra de Rosdolsky deve ser vista como roteiro inexcedível do itinerário da construção da crítica da economia política tal como ela pode ser feita numa primeira navegação. E aqui a menção a Platão é mais que metafórica. Tratase, no caso de Marx, de ver sua obra depois de os Grundrisse, a partir da assim Contribuição à crítica da economia política, de 1859, como uma segunda e, potencialmente, mais rigorosa navegação porque guiada por método de exposição rigorosamente desenvolvido em suas implicações dialéticas, como nos mostrou Marcos Müller (Müller, 1982).

Já vai longe o tempo em que a chamada "questão do método" tomou conta do debate no campo das ciências sociais e do marxismo em particular. Se houve exageros, se houve "fetichizações", se houve mesmo certo abuso na petição da explicitação das "condições de possibilidade do co- nhecimento", não é o caso de se interditar a discussão sobre o método porque é preciso ver nela questão inescapável. Mesmo Hegel, aquele que mais explicitamente se colocou denunciar o criticismo kantiano, como tautológico ou aporético, teve que se haver com a questão epistemológica, a seu modo, como se vê na Fenomenologia do Espirito. Veja-se o que diz Jean Hippolite:

Em suas obras filosóficas de Iena, Hegel havia criticado toda propedêutica à filosofia. Não é possível ficar-se, continuamente como Reinhold, no pórtico do templo. A filosofia não é nenhuma lógica como 'Órganon' que trata do instrumento do saber antes de saber, sem um amor à verdade que não fora a possessão mesmo da verdade. Não, a filosofia é ciência e, como defende Schelhing, ciência do Absoluto. Em vez de permanecer na reflexão, no saber sobre o saber, há que fundir-se, direta e imediatamente, no objeto a conhecer-se, chame-se este Natureza, Universo ou Raそão Absoluta.

[...] Em sua introdução à Fenomenologia Hegel repete suas criticas a uma filosofia que não fosse mais que teoria do conhecimento. E, contudo, a Fenomenologia, como assinalaram todos seus comentaristas, marca em certos aspectos um retorno ao ponto de vista de Kant e Fichte.

[...] Hegel que havia criticado anteriormente toda propedêutica, insiste agora na necessidade de situar-se na perspectiva da 
consciência natural e de levá-la, progressivamente, ao saber filosófico. Impossivel começar pelo saber absoluto (Hippolite, 1991, p. 8,9 e 10).

A Fenomenologia do Espirito, de Hegel, que completa em 2007, duzentos anos, representa na obra de Hegel o momento fundante de seu sistema, que se realizará, em 1812, com a publicação da Ciência da Lógica. $\mathrm{Na}$ Fenomenologia do Espirito, há a volta a Kant e a Fichte, a volta às petições de condições de possibilidade do conhecimento para dar uma resposta diferente a essas exigências, uma resposta, que, reconhecendo a consciência imediata como ponto de partida necessário da caminhada do espírito, faz da caminhada, da "odisséia da consciência", do seu processo de aprendizado, de sua presença no mundo, o itinerário enriquecedor da consciência, que, em seu périplo pelo mundo, tanto transforma-o quanto é transformado por ele. Essa problemática foi inexcedivelmente posta por Karel Kosik num texto, justamente, célebre, que aproximou a Fenomenologia do Espirito, de Hegel, de Anos de aprendizagem de Wilhelm Meister, de Goethe, e de O Capital, de Marx, e todos os três da Odisséia, do Homero (Kosik, 1976, p. 166).

No que interessa neste texto, buscou-se, sem forçar indevidas afinidades, tanto ver paralelismos na relação entre a $\mathrm{Fe}$ nomenologia do Espirito e a Ciência da Lógica, de
Hegel, e os Grundrisse e O Capital de Marx, cabendo, a partir disso, reconhecer que Rosdolsky, como estudioso de os Grundrisse de Marx, ocupa na história do pensamento marxista lugar equivalente ao que Alexander Kojève e Jean Hippolite têm no relativo à obra de Hegel.

É bem conhecida a passagem de Marx na qual ele explica as razões que o teriam levado a não publicar a Introdução à Contribuição à crítica da economia política, de 1859. Diz ele no Prefácio dessa obra: "Ainda que houvesse esboçado uma introdução geral, prescindo dela, pois, bem pensada a coisa, creio que é adiantar resultados que devem ser demonstrados, o que seria um estorvo. O leitor que queira, realmente, me seguir deverá estar disposto a transitar do particular ao geral" (Marx, 1972, p. 34).

Em outro momento, Marx foi ainda mais explícito em sua afirmação sobre a impropriedade de uma apresentação de categorias analíticas separadas da exposição de suas presentificações e conexões necessárias. Para ele o modo necessário, legítimo, de aparecimento e desenvolvimento dos conceitos, do ponto de vista do método dialético, impõe que esses conceitos emerjam da própria explicitação do objeto, de sua efetiva apropriação-exposição. Nesse sentido, para Marx a apreensão do conceito pressupõe que se o acompanhe em toda a sua caminhada, em sua odisséia de aparições-metamorfoses. Diz Marcos Muller: 
O método dialético quer superar essa exterioridade do conhecimento em relação ao objeto e a concepção instrumental de método ai presente. Este exige que o conbecimento aprenda as determinações do conteúdo no próprio movimento pelo qual elas se desdobram, estabelecendo a conexão necessária e, imanente entre elas (Müller, 1982, p. 24).

De todo modo, Marx e Hegel, críticos do apriorismo metodológico, sentiramse obrigados a escrever obras equivalentes ao "discurso do método" e é isso, decisivamente, que importa reter, configurando assim tanto a importância da Fenomenologia do espirito, para a obra de Hegel, quanto de os Grundrisse, para a obra de Marx. É a luz dessa questão teórica de grande envergadura que se deve apreciar a leitura de Rosdolsky de os Grundrisse.

Hegel retomou a problemática do conhecimento na Fenomenologia do espirito, dando-lhe um tratamento rigorosamente compatível com a sua dialética. Marx também fará incursão no campo metodológico que a introdução geral aos Grundrisse der Kritik der politischen Ökonomie, obra escrita, entre 1857 e 1859, e publicada apenas em 1939 (Marx, 1989).

Publicado sintomaticamente em 1968, o livro de Rosdolsky, Gênese e estrutura do 'Capital' de Karl Marx, é obra singular no campo das ciências humanas e sociais. De fato, nenhuma grande teoria desse campo do conhecimento mereceu de seus estudiosos uma reconstituição tão meticulosa, quanto iluminadora. Se os Grundrisse representa o "laboratório teórico" de Marx, numa metáfora conhecida, o livro de Rosdolsky é o diário da vida do laboratório, o inventário dos métodos e procedimentos, do material e modos de fazer, dos protocolos de ação e síntese de resultados.

De fato, se Marx e Hegel se sentiram obrigados a ajustar contas com a tradição da teoria do conhecimento, superando-a, o livro de Rosdolsky diferencia-se em um sentido essencial daquelas grandes obras de Kojève e Jean Hippolite. Para esses autores, tratou-se de analisar uma obra acabada, redigida com rigor e forma necessários, como é a Fenomenologia do espirito. Para Rosdolsky o que se pôs foi buscar respostas, concatenar, esclarecer, desvelar o que o texto de um rascunho só pode apresentar fragmentariamente, cifradamente, sem os cuidados que a "exposição" rigorosa exige.

Não é pequeno elogio o que se faz aqui à obra de Rosdolsky ao aproximá-la de Gênese e estrutura da fenomenologia do espirito de Hegel, de Jean Hippolite, publicado em 1946 (Hippolite, 1991), e à $A$ dialética do senhor e do escravo em Hegel; A Antropologia e o Ateísmo em Hegel; $A$ dialética do real e a idéia da morte em Hegel, que reúnem o conteúdo dos 
cursos e conferências proferidas por Kojève na Escola de Altos Estudos, em Paris, entre 1933, 1939, cursos que mobilizaram toda a inteligência francesa daquele tempo, de Sartre a Lacan (Kojève, 1987; 1985; 1972).

Há ainda outra razão para valorizar com ênfase a obra de Rosdolsky. É que os Grundrisse contém, em estágio de desenvolvimento preliminar, o essencial do projeto completo dos seis livros que Marx planejou escrever: o sobre capital; o sobre a propriedade da terra; o sobre o trabalho assalariado; o sobre Estado, o sobre comércio exterior; e o sobre o mercado mundial e as crises. Dos seis livros projetados, apenas os três primeiros foram publicados e, ainda assim, em estágios diferenciados de acabamento. De fato, os Grundrisse, na obra de Marx, prefigura a totalidade da crítica da economia política, tal como essa pode aparecer em sua primeira presentificação, como totalidade, que, incluindo todos os elementos constitutivos do real, só pode apresentar, inicialmente, esses elementos num altíssimo grau de abstração, que é o modo necessário de exposição do real, que só pode se pôr, legitimamente, isto é, inteligivelmente, como ser que se desdobra, que se desenvolve pela extrinsecação de suas contradições, pela ação inescapável do negativo, "do que tudo nega, e com razão", como Goethe o surpreendeu na figura de Mefistófeles.
Assim, os Grundrisse, sendo exposição da totalidade, ainda não desdobrada, a única que Marx, efetivamente, concluiu, já que incompleto ficou $O$ Capital, contém certos temas, certas discussões, certas questões que só foram discutidas por Marx nesse texto, questões como a historicidade da lei do valor, sobre o sentido do socialismo, que têm atualidade e relevância decisivas para a afirmação da insuperável pertinência do marxismo para o mundo contemporâneo.

É exatamente essa circunstância que explica a extraordinária contribuição representada pelos capítulos 28 e 29 do livro de Rosdolsky que são, respectivamente: "O limite histórico da lei do valor. Observações de Marx sobre a ordem socialista"; e "A reificação das categorias econômicas e a "verdadeira concepção do processo social de produção" ". Nesse sentido, o livro de Rosdolsky é um instrumento, combativo e informado, tanto para a denúncia e o desmascaramento do ignonimioso do mundo contemporâneo quanto um convite para a construção das melhores promessas emancipatórias, malgré tout, que continuam a nos mobilizar. 


\section{Referências bibliográficas}

BENJAMIN, César (Org.). Marxe o Socialismo - 2006. 2. ed. São Paulo: Expressão Popular, 2006.

DUSSELL, Enrique. La producción teórica de Marx, un comentario a los Grundrisse. México, Siglo XXI, 1985

HIPPOLITE, Jean. Génesisy

estructura de la fenomenología del Espiritu de Hegel. 2. ed. Trad. esp. Barcelona: Ediciones Península, 1991.

KOJÈVE, Alexandre. La dialéctica de lo real y la idea de la muerte en Hegel. Trad. esp. Buenos Aires, La Pléyade, 1972.

KOJÈVE, Alexandre. La Antropología y el ateismo en Hegel. Trad. esp. Buenos Aires, La Pléyade, 1985.

KOJÈVE, Alexandre. La dialéctica del amo y del esclavo en Hegel. Trad. esp. Buenos Aires, La Pléyade, 1987.

KOSIK, Karel. Dialética do concreto 2. ed. Trad. port. Rio de Janeiro: Paz e Terra, 1976.

MANDEL, Ernest. $A$ formacão do pensamento econômico de Karl Marx. Trad. port. Rio de Janeiro, Zahar Editores, 1968.
MARX, Karl. Fondements de la critique de l'Économie Politique. Trad. Francesa, Paris, Éditions Anthropos, 1968.

MARX, Karl. Introducción general a la crítica de la Economía Política/1857. Trad. esp. 6. ed. Buenos Aires, Cuadernos Pasado y Presente, n. 1, 1972.

MARX, Karl. Glosas Marginales al "Tratado de economia politica de Adolph Wagner". In: DOBB, Maurice (Org.). Estudios sobre El Capital. Trad, esp., 2. ed., México, Siglo XXI, 1977

MARX, Karl. Elementos fundamentales para la crítica de la Economía Política (Grundrisse) 1857-1858. Trad. esp. v. 16. México/Espanha/Argentina/ Colombia, Siglo XXI, Editores, 1989.

MARX, Karl; ENGELS Friedrich. Cartas sobre El Capital. Trad. esp., Barcelona Editorial Laia, 1974

MEHRAV, Perez.

Social-democracia e austromarxismo. In: HOBSBAWM, Eric (Org.). História do Marxismo. Trad. port. Paz e Terra, v. 5, 1985.
MÜLLER, Marcos L. Exposição e método dialético em $\mathrm{O}$ Capital. In: Boletim SEAF, n. 2. Belo Horizonte: SEAF, 1982.

PREOBRAZHENSKI, Evgeni. La Nueva Económica. Cuadernos de Pasado y Presente, n. 17 e 18, Trad. esp. Buenos Aires, 1968.

RABINBACH, Anson G. Roman Rosdolsky 1897-1967: an introduction. In: New German Critique, n. 1, Autumn, 1974

ROSDOLSKY, Roman. La Significación de "El Capital" para la Investigación Marxista Contemporânea. In: FAY, Victor (Org.). Leyendo el Capital. Trad. esp. Editorial Fundamentos, 1972. ROSDOLSKY, Roman. A memoir of Auschwitz and Birkenau. In: Monthly Review, v. 3, n. 8, jan. 1988 .

ROSDOLSKY, Roman. Gênese e estrutura de O Capital de Karl Marx. Trad. port. Rio de Janeiro: EDUERJ/Contraponto, 2001.

RUBIN, Isaak. Ensayos sobre la Teoria Marxista del V alor. Trad. esp. Buenos Aires, Cuadernos de Pasado y Presente, n. 53, 1974.

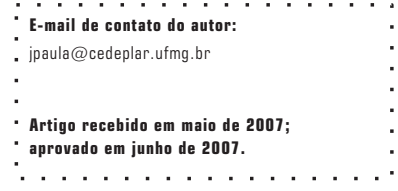

